Portland State University

PDXScholar

2-11-1993

\title{
Occurrence of Phonological Processes Within Two Pragmatic Categories in Normal and Speech- Delayed Children
}

Betsy Ann Bergman

Portland State University

Follow this and additional works at: https://pdxscholar.library.pdx.edu/open_access_etds

Part of the Speech and Rhetorical Studies Commons

Let us know how access to this document benefits you.

Recommended Citation

Bergman, Betsy Ann, "Occurrence of Phonological Processes Within Two Pragmatic Categories in Normal and Speech-Delayed Children" (1993). Dissertations and Theses. Paper 4532.

https://doi.org/10.15760/etd.6416

This Thesis is brought to you for free and open access. It has been accepted for inclusion in Dissertations and Theses by an authorized administrator of PDXScholar. Please contact us if we can make this document more accessible: pdxscholar@pdx.edu. 
AN ABSTRACT OF THE THESIS OF Betsy Ann Bergman for the Master of Science in Speech Communication: Speech and Hearing Science presented February 11, 1993.

Title: occurrence of Phonological Processes Within Two Pragmatic Categories in Normal and Speech-Delayed Children

APPROVED BY MEMBERS OF THE THESIS COMMITTEE:

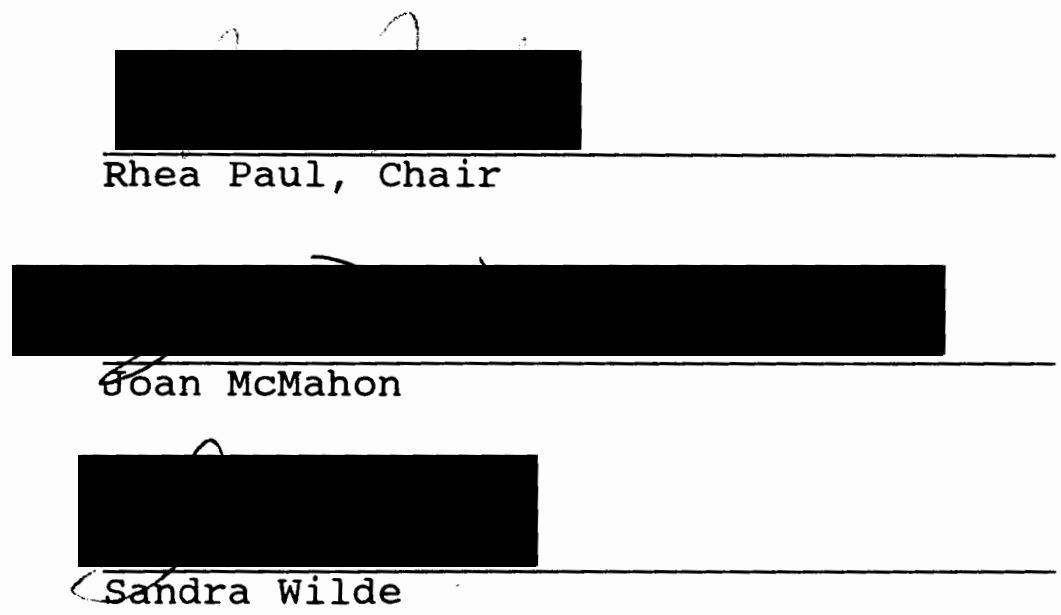

Research into the eventual suppression of phonological processes among children has centered on the influence of phonetic context and semantic-syntactic factors. Researchers have described various factors that would account for the variability found in normal and speech-delayed children's use of phonological processes. Researchers have found associations between phonological process use and language form and content, although there is 
a paucity of information pertaining the effect of language use on phonological performances.

This study examined the phonological process use within two pragmatic functions-assertive and responsive utterances-used by 15 normally developing and 15 speech-delayed 3-year-olds. These groups were matched for age, sex, and socioeconomic status, all passed a hearing screening at $25 \mathrm{~dB}$ and scored at least 85 on the Bayley Scales of Infant Development or the Stanford-Binet Intelligence scale.

A 10-minute parent/child speech sample of each 3-year-old was orthographically and phonetically transcribed. Each first occurrence utterance was coded as either assertive or responsive, depending on the particular pragmatic function it served. Percentage of phonological process use was determined for both groups within each pragmatic category, after analysis in the Pepper Program. Data were analyzed for significant differences between the two groups in the percentage of phonological processes used within the assertive and responsive categories. Results indicated that the speech-delayed group used more processes in both categories, although pragmatic function of the utterances did not have a significant effect on percentage of phonological processes used by either group. It was noted that children in the speech-delayed group were only mildly delayed, thus making them fairly intelligible to their listeners. Both groups were more assertive than 
responsive and used longer utterances during assertive speech acts; however, neither factor appeared to have any bearing on their phonological performances.

It was concluded that the two groups appeared to show no significant difference in their phonological performances when comparing one pragmatic category to the other. Results indicated that the assertive speech acts examined held no motivation factors that influence the phonological performance of normal or mildly speech-delayed 3-year-old when compared to responsive speech acts. 
OCCURRENCE OF PHONOLOGICAL PROCESSES

WITHIN TWO PRAGMATIC CATEGORIES

IN NORMAL AND SPEECH-DELAYED CHILDREN

by

BETSY ANN BERGMAN

A thesis submitted in partial fulfillment of the requirements for the degree of

\author{
MASTER OF SCIENCE \\ in \\ SPEECH COMMUNICATION : \\ SPEECH AND HEARING SCIENCE
}

Portland State University

1993 
TO THE OFFICE OF GRADUATE STUDIES:

The members of the committee approve the thesis of Betsy Ann Bergman presented February 11, 1993.

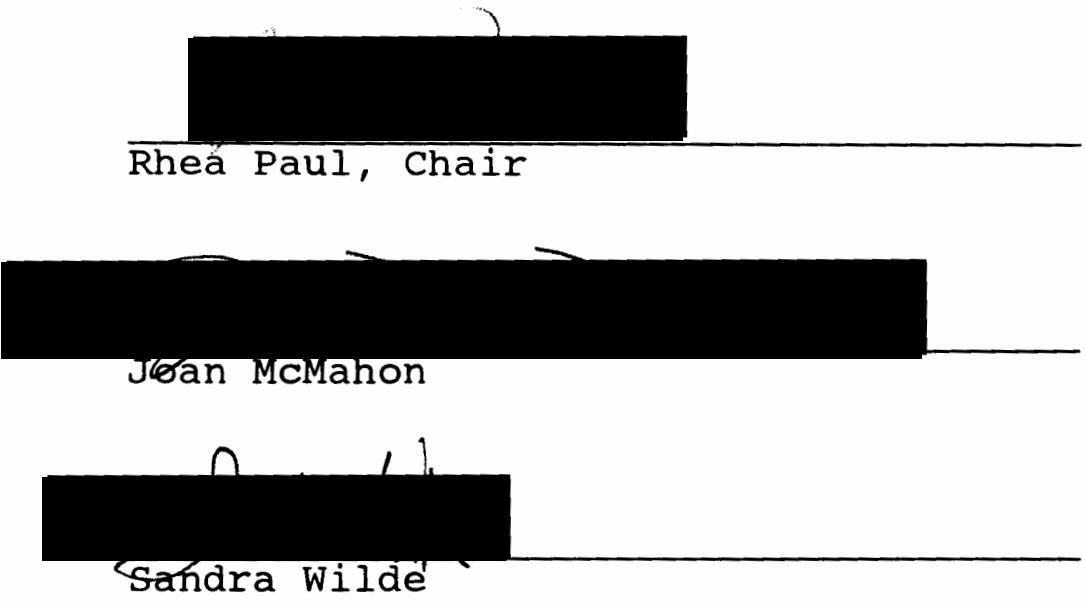

APPROVED:

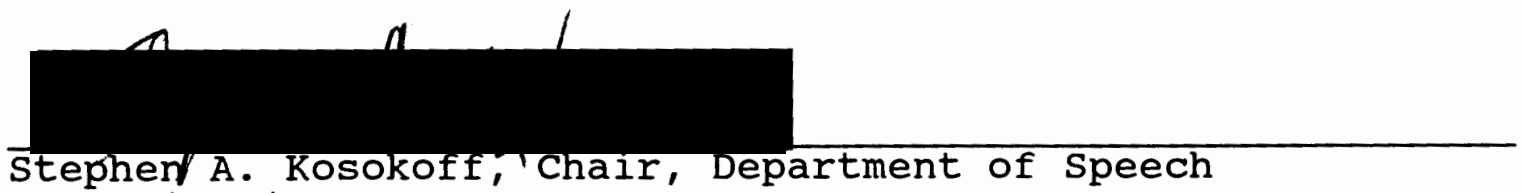
Communication

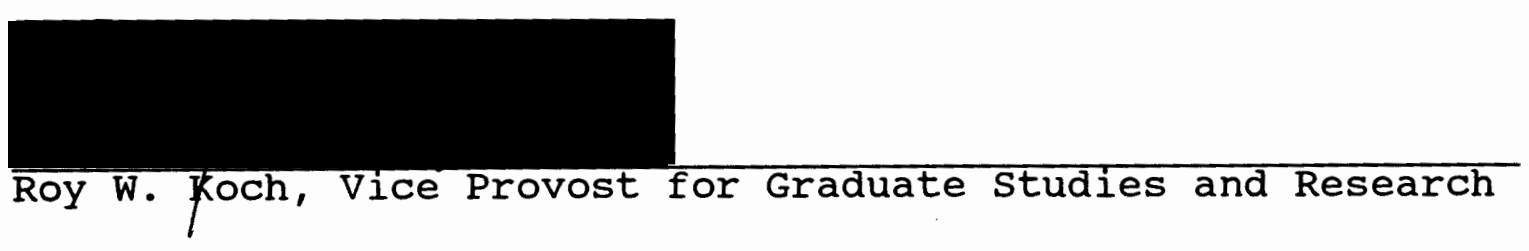




\section{ACKNOWLEDGEMENTS}

I wish to express my sincerest appreciation to the people who advised and guided me through the long process of this thesis, including Rhea Paul and Joan McMahon. I also thank Sandra wilde for serving on my thesis committee.

Words cannot express my gratitude to my fiance Brad, for his encouragement, support, computer assistance, and love. Without his clear vision of reality, I could not have completed this project. . . "Hey Brad, I can see the ongford!" 
TABLE OF CONTENTS

PAGE

ACKNOWLEDGEMENTS . . . . . . . . . . . . . iii

LIST OF TABLES . . . . . . . . . . . . . . . . vi vi

CHAPTER

I INTRODUCTION AND STATEMENT OF PURPOSE • . 1

Introduction . . . . . . . . . 1

Statement of Purpose . . . . . . . 3

Definition of Terms . . . . . . . 3



Normal Phonemic Acquisition . • . • 6

Normal Phonological Development . . 7

Inconsistent Pronunciation . . . . 8

Influences on Pronunciation . . . . 11

Phonetic context

Morphological and syntactic context

Semantic contexts

Stimulus Presentation Influences

Pragmatic Contexts

METHODS AND PROCEDURES . . . . . • • • .

Subjects . • . • . . . . . . .

Subject Description at Intake:

Age 2

Subjects in Present study:

Age 3 


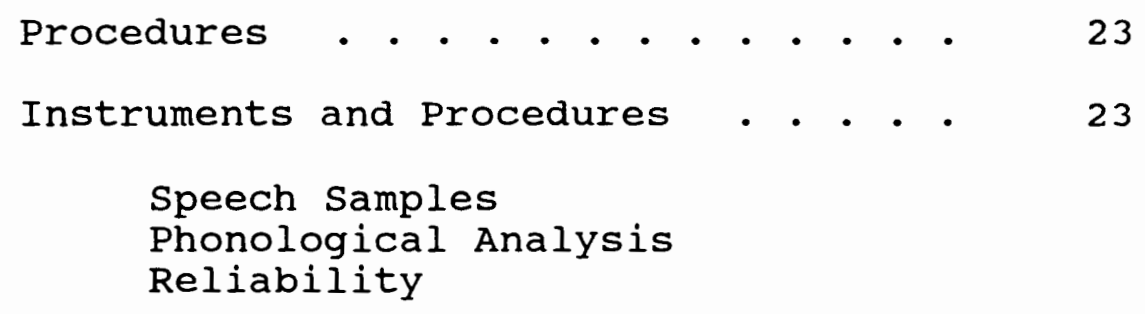




\section{LIST OF TABLES}

TABLE

PAGE

I Decline of Phonological Process Occurrence in children Between the Ages of 3 and 5 (Haelsig \& Madison, 1986

Summary of Demographic Data . . . . .

Results of One-Tailed $t$ Tests Comparing

Mean Percentage of Phonological

Process Use in Two Pragmatic

Categories for Two Diagnostic

Groups

Results of One-Tailed $t$ Tests comparing Mean Use of Phonological Processes Between Normal and Delayed Groups in Both Pragmatic Categories

Results of One-Tailed $t$ Test Comparing Average Difference Between Phonological Process Use in Assertive and Responsive Utterances for Normal and Speech-Delayed Groups . . . . . . . . . . . . .

VI Results of $\underline{t}$ Tests Comparing Percentage of Unintelligible Words in Assertive and Responsive Utterances within the Normal and Speech-Delayed Groups

Results of a one-Tailed $t$ Test comparing the Average Difference in Each Subject's Unintelligibility Between the Normal and speech-Delayed Groups

Results of one-Tailed $t$ Test Comparing Average Percentage of Assertive and Responsive Utterances in the Normal and Speech-Delayed Speech Samples . 
IX Results of one-Tailed $t$ Test Comparing Mean Length of Response Within

the Assertive and Responsive

Utterances in the Normal and

Speech-Delayed Groups . . . . . . .

$x$ Results of a One-Tailed $t$ Test Comparing the Average Difference in Each

Subject's Length of Response

Between Assertive and Responsive

Utterances Between Normal and

Speech-Delayed Groups . . . . . . . 
CHAPTER I

INTRODUCTION AND STATEMENT OF PURPOSE

INTRODUCTION

Phonological processes are a description of the systematic changes that occur in a child's speech in order to simplify production (Weiss, Gordon \& Lillywhite, 1987). During speech acquisition, children attempt to match the standard adult productions. When adult target forms are too complex for the child's current production system, phonological simplification processes often occur. Through linguistic experience, phonological processes are eventually modified and suppressed so that the pronunciation comes to match that of the adult. However, during speech development, the occurrence of phonological processes has been found to be variable. Studies have shown that certain factors increase the occurrence of correct speech productions during speech acquisition (Campbell \& Shriberg, 1982; Gallagher \& Shriner, 1975a; Paul \& Shriberg, 1982). The identification of those components that decrease phonological process use, thus enhancing the production of the adult target, would be beneficial in the understanding of phonological processes. 
The main body of research concerning the eventual suppression of phonological processes among children has focused heavily on the influence of phonetic context and semantic-syntactic factors (Gallagher \& Shriner, 1975a; Paul \& Shriberg, 1982; Shriberg \& Kwiatkowski, 1980). Researchers have attempted to provide information about these factors that would account for the variability found in children's use of phonological processes. Although associations have been found between phonological process use and language form and content, there is a paucity of information pertaining to the effect of language use on phonological performance. Aside from the phonetic context and semantic-syntactic factors, it is possible that specific pragmatic contexts may motivate children to use the best pronunciation they have available in order to insure that their message gets across. This internal motivation, stemming from interpersonal concerns, may increase their usage of adult phonological forms, thus enhancing intelligibility and communicative success. Associations made between specific pragmatic functions and phonological performance could be used to better understand children's progression toward adult phonological forms. Also, knowing whether pragmatic contexts have the same or different effects on the speech of normal and delayed speakers would have clinical implications for therapeutic techniques. 
STATEMENT OF PURPOSE

It is the purpose of this study to determine if there are any significant differences in the use of phonological simplification processes by 3-year-old children when producing utterances with differing pragmatic functions, specifically, assertive and responsive utterances. In addition, the study attempts to determine whether there are any significant differences in the effect of these two pragmatic categories on the phonological performance of normal as opposed to speech-delayed children.

The research hypothesis tested in this study is as follows: There will be a significantly greater number of phonological simplification processes used on words expressing responsive as opposed to assertive speech acts in both normal and speech-delayed 3-year-olds. It is believed that assertive speech acts will have enhanced pronunciation because there is more personal motivation to increase communication with the listener during this speech act. For statistical purposes, the null hypothesis is that no differences will be found in phonological performance between words used to express assertive and responsive speech acts made by normal and speech-delayed children.

$$
\text { DEFINITION OF TERMS }
$$

The following operational definitions were utilized within this study: 
1. Assertiveness: The intention of taking a turn in a conversation without request from a partner (Fey, 1986).

2. Broad phonemic transcription: A child's representation of a word using a phonetic alphabet, without use of diacritics (Ingram, 1981).

3. Phonological processes: A tendency for a child to systematically simplify, or alter, production of natural classes of sounds (Ingram, 1981).

4. Phonological process disorders: Disturbances in the organization or representation of linguistic rules for making sounds (Ingram, 1981).

5. Pragmatic function: The use of language for different goals or functions and the use of information from the context to determine what we say in order to reach goals (Lahey, 1988).

6. Pragmatics: The use of language for different goals or functions and the use of information from the context to determine what we say in order to reach goals (Lahey, 1988).

7. Responsiveness: Involving the intention to reply or conform to a partner's previous request or by substantiation of nonrequestive acts spoken previously by a partner (Fey, 1986).

8. Speech-delayed: Less mature phonological system than age equivalent peers, although speech acquisition is still following the normal sequence of development (Leonard, 1973) 
CHAPTER II

REVIEW OF THE LITERATURE

NORMAL PHONEMIC ACQUISITION

Speech sound acquisition generally shows systematic and orderly development among young children. However, children's progression toward adult phonological forms often results in lengthy periods of trial and error attempts at correct speech productions (Weiss et al., 1987). Systematic sound charges are characteristic and very often occur in the speech of both normal and speech-delayed children between the ages of 18 months and 4 years.

There are two general types of speech sound assessment used to describe the variety of speech sounds produced in young children: phonetic and phonological. The assessment of children's phonetic or articulatory development is concerned with the acquisition of motor abilities associated with speech sound production. Studies of phonetic development in young children generally show a wide range of variability; however, phonemic production becomes more stable with age (Owens, 1984). When phonemes are grouped into classes, studies reveal that children generally acquire phonemes in a predictable order. Stoel-Gammon and Dunn 
(1984) specified age ranges of phonemic acquisition, which are as follows:

1. Vowels tend to develop prior to consonants and are produced with $100 \%$ accuracy by 3 years of age.

2. Based on manner of consonant articulation, stops, nasals, and glides are generally acquired before liquids, affricates, and fricatives.

3. Based on place of consonant articulation, the order is usually glottal, then labials, velars, alveolars, dentals, and finally palatals.

4. The majority of phonemes are mastered in the initial position prior to the final position, although rapid development of correct production of final consonants occurs between 2 and 3 years of age. However, fricatives differ from the norm and usually develop first in the final position.

5. Single consonants are mastered prior to clusters. Clusters are generally mastered between 7 and 8 years of age, although some clusters may begin to be produced at 2 years.

\section{NORMAL PHONOLOGICAL DEVELOPMENT}

The analysis of children's phonological development consists of the sounds that are produced and the child's knowledge of more abstract linguistic rules. According to Ingram (1981), phonological development begins with preverbal vocalizations, which are important precursors to 
speech development. Within 12 months these prelinguistic utterances are tailored into voluntary vocalizations in the form of single $\mathrm{CV}, \mathrm{VC}$, double, or reduplicated syllablesCVCV. Single words are produced and syllable types are expanded with age (Weiss et al., 1987). A variety of syllable shapes are added by age 2, including CVC, CVCV-non-reduplicated, CVCVC, and some initial and final clusters (Stoel-Gammon \& Dunn, 1984).

Phonological processes operate to simplify the production of these representations, resulting in the differences between the child's pronunciation and the conventional adult pronunciation. Phonological processes are used by many normally developing children up to the age of 4 , with the majority of the phonological processes no longer being produced after that age (Shriberg \& Kwiatkowski, 1980). Aside from normally occurring processes, phonologically delayed children will exhibit abnormal phonological processes, or the use of processes will extend beyond the normal developmental period (Weiss et al., 1987).

Stoel-Gammon and Dunn (1984) outlined three major categories of phonological processes: syllable structure processes, substitution processes, and assimilation processes. The syllable structure processes are modifications of the syllable structure, varying from the conventional adult form. Assimilation processes refer to sounds or sound segments that are changed to become more 
similar to nearby sounds or segments of sounds (Edwards \& Shriberg, 1983). Sound changes may either be progressive assimilation-alterations of sounds to become more like preceding sounds-or regressive assimilation-sounds that are influenced by following sounds (Weiss et al., 1987). Substitution processes occur when one phoneme is replaced by another phoneme and the role of phonetic context is not a factor.

The child's phonological system goes through periods of change in process use that eventually allow for more adult-like pronunciation as the child acquires experience with language (Edwards \& Shriberg, 1983) and practice in articulation of words. Campbell and Shriberg (1982) noted that stampe's (1973) findings suggest that phonological processes are suppressed, eventually allowing for consistent adult-like pronunciation.

Haelsig and Madison (1986) demonstrated the decline of phonological process occurrence in 50 children between the ages of 3 and 5 years. The percentage that each process was used at 3 and 4 years is outlined in Table I. This data provide clear evidence that normal children gradually reduce their use of phonological process with age.

\section{INCONSISTENT PRONUNCIATION}

During the period of phonological development, children often show variable pronunciation of words, what the researchers who analyze phonetic differences have referred 
TABLE I

DECLINE OF PHONOLOGICAL PROCESS OCCURRENCE IN CHILDREN BETWEEN THE AGES OF 3 AND 5

(HAELSIG \& MADISON, 1986)

\begin{tabular}{lcc}
\hline \multicolumn{1}{c}{ Phonological processes } & at 3 years & $\begin{array}{c}\% \text { used } \\
\text { at } 4 \text { years }\end{array}$ \\
\hline Liquid simplification & 48 & 24 \\
Unstressed syllable deletion & 38 & 27 \\
Cluster reduction & 30 & 10 \\
Assimilation & 30 & 14 \\
Final consonant deletion & 22 & 8 \\
Stopping & 14 & 8 \\
Fronting & 10 & 8 \\
\hline
\end{tabular}

to as "articulatory inconsistencies" (Gallagher \& Shriner, 1975a, p. 168; Winitz, 1969, p. 167) or "inconsistency of misarticulation" (Spriestersbach \& Curtis, 1951). Many researchers have investigated the area of inconsistent pronunciation found in the speech of children with seemingly normal speech development and those with deviant speech patterns. These researchers note that frequently mispronounced speech sounds are occasionally produced correctly in he utterances of children with both normal and deviant phonological processes (Amidon, 1941; Curtis \& Hardy, 1959; Gallagher \& Shriner, 1975a, 1975b; Wilson, 
1945). Olmstead (1971) confirms the coexistence of successes and errors on the productions of the same phoneme through the analysis of the performances of individual children. Notably, each child involved in the study revealed at least one phoneme which had both a correct production and an incorrect production, including $65 \%$ of the children who produced, from their entire phoneme repertoire, more than 15 phonemes both correctly and incorrectly, and $50 \%$ of these children who produced at least 19 phonemes in the same manner. This researcher concluded from his findings that the coexistence of correct and incorrect productions was the most common pattern among the phonemes expressed and the most common pattern among the children. Olmstead further suggests that the process of phonological acquisition is not an all or nothing affair. The phonological productions of children in the developmental period appear to be characterized by both successes and errors on the same sounds in different contexts.

The existence of the previous research, which hypothesizes that both normal and speech-delayed children occasionally exhibit adult-like phonology in the midst of errors patterns, suggests that these children are capable of coordinating their behavior in such a way that the adult phonological rules are sometimes fully observed (Olmstead, 1971). However, for a variety of reasons, some phonological performances involve simplification of target words, 
creating a discrepancy between the child's underlying representative competence and his actual performance.

Questions have been raised in the research concerning the particular factors that contribute to the inconsistencies found in the articulation and phonological processes used by children. This present research has been conducted in an attempt to analyze the various linguistic variables thought to influence children's accuracy of speech productions. Attention has mainly been focused on the underlying syntactic and pragmatic variables occurring in conjunction with the phonological processes.

\section{INFLUENCES ON PRONUNCIATION}

\section{Phonetic context}

Several studies looked at phonetic influences on children's pronunciation. Curtis and Hardy (1959) and snow (1963) researched the articulatory inconsistencies during production of various phonemes and the nature of the sounds preceding or following the test sounds. Their results suggest that the phonemic context affects speech production. The researchers suggest that there appears to be a relationship between the position of a sound in a word and the production of the sound.

Further analysis of the effects of phonetic context on articulation inconsistencies of /s and /z/ in children suggests a relationship between surrounding phonemes and 
errors on target sounds. Gallagher and Shriner (1975b) found that when consonants followed either the /s/ or $/ \mathrm{z} /$ phonemes, the accuracy of production of both phonemes was decreased. Consonants which preceded the /s/ or /z/ phonemes did not show the same contextual effect. The degree of influence of the consonants that followed the /s/ and /z/ phonemes was determined by these researchers to be the effect of co-articulation. The motor sequencing patterns of specific phonemes and their eventual production were affected by the manner and place of articulation of the consonants which directly followed them, constituting a phonological environment which resulted in inconsistent articulation.

Aside from the immediate phonetic environment, another factor pertaining to the broader phonological context has been shown to influence variability in speech production. Faircloth and Faircloth (1970) investigated the differences in articulatory behavior in connected speech and in single isolated words in a speech disordered child. The results revealed that the subject consistently misarticulated and omitted sounds during spontaneous speech. However, when the same words were produced in isolation, misarticulations decreased by $21.14 \%$. Consequently, the researchers judged the child's speech during isolated word production as more intelligible than seen in connected speech. 
Panagos, Quine, and Klich (1979) investigated the influence of phonetic context on the articulation of children with phonological deficits. The phonetic structural variations in which the accuracy of production was assessed were word structure and word position. Their results revealed that both consonant and context difficulty, in phonologically complex structures, determined the accuracy of production. These authors found that during structurally complex utterances, the children tended to simplify their speech productions, thus decreasing their intelligibility.

Morphological and syntactic context

According to Paul and Shriberg (1982), phonological productions show interaction with syntax and morphology in speech-delayed children. These researchers analyzed utterances from 39 speech-delayed children. The children were then categorized into four classifications based on their speech and syntactic performances. It was revealed that half of the children who showed delays in both speech and syntax increased their speech production accuracy in complex phonetic contexts that included a morphological marker. The enhanced speech was found to match their syntactic capabilities, suggesting that the degree of syntactical competence positively influences speech output. other researchers suggest that syntactic factors may influence phonological performance in a different way. 
Panagos et al. (1979) found that syntactically complex structures (e.g., passive sentences) resulted in more simplification of phonological productions than did syntactically simpler contexts (e.g., active sentences).

Leonard (1971) believed that if motivation to improve speech performances was enhanced during situations which required expanded communication to correctly inform listeners, then specific speech sounds which carry a high information value relative to the meaning of an utterance would be produced accurately more than speech sounds with low information value. The results of this study revealed that when the production of the phoneme /z/ was deemed necessary for the transmission of meaning to the listener, as in its role as a plural marker, it was produced correctly. When this phoneme was not necessary for the listener to attain meaning in the utterance, it was more likely to be omitted. The information suggests that an increased effort is made toward correct production of speech sounds when the sounds are necessary for conveying meaning.

\section{Semantic Contexts}

Interactions between phonology and semantics have been investigated by Camarata and schwartz (1985) with regard to productions of action and object words. These results suggested that children increase their usage of correct adult forms when producing object words or nouns, as opposed to action words or verbs. Shriberg and Kwiatkowski (1980) 
found similar semantic influences on pronunciation, with inconsistencies revealed in the phonological behavior of 3-year-olds during productions of nouns as opposed to verbs.

\section{Stimulus Presentation Influences}

Further research has suggested that the presentation of stimuli during testing also influences the articulation of speech sounds in children. Siegel, Winitz, and conkey (1963) observed that during imitative presentation of words, 5-year-olds showed more correct productions of speech sounds than during spontaneous production of the identical words. These results suggest that articulatory inconsistencies may also be influenced by a direct adult model enhancing the intelligibility of the children's speech.

\section{Pragmatic Contexts}

The foregoing studies which examined syntactic, semantic, and interpersonal factors in relation to phonetic and phonological performance, have all attempted to identify contexts that would account for the pronunciation inconsistencies found in children. In addition to these factors, however, pragmatic function may also impact on children's phonetic and phonological performance. A few researchers have studied how interactive communication between the speaker and his listener has been a significant variable in speech productions. 
Wells (1981) noted that even with the emergence of first word vocalizations, children have interpersonal purposes. As the children's linguistic systems develop, their pragmatic repertoire also matures and expands. During communicative interactions, various pragmatic functions are utilized, either on demand from the listener or by initiation of the speaker himself. According to the pragmatic theory, every verbal communicative act produced by children has a specific intention or cognitive plan. The meaning of the act is thus intended to be interpreted by the listener (Levy, Schlesinger \& Braine, 1988), and in order to accomplish communicative goals, children must make themselves understood.

Weiner and Ostrowski (1979) found that the speaker's intention to clarify an utterance positively motivated them to make sound production changes. This investigation revealed that the need to be understood during communication appeared to have the most influence on the children's articulation. The subjects originally produced a greater percentage of misarticulations when not clarifying an utterance for their listener. However, upon listener confusion, the misarticulations were altered to become loser approximations of adult speech productions.

Gallagher (1977) investigated the syntactic and phonological behavior of children who believed that they were misunderstood by their listeners. She found that the 
children did indeed vary their responses, both syntactically and phonologically to help clarify their original utterance. It was shown that the phonetic changes were primarily substitution of consonants in the final position of words. Also, $50 \%$ of the phonetic changes were self-corrections which were closer representations of adult phonological forms than their prior utterance. This study suggests that certain pragmatic functions are associated with the revision of both syntactical and phonological structures.

Campbell and Shriberg (1982) examined production of speech sounds in two pragmatic functions by speech-delayed children. They examined conversational speech samples. Information in the sentence that referred to previously given or presupposed elements were termed topics, and the newest information in the sentence was termed comments. Each word in the utterance was coded as to pragmatic function and phonetically transcribed to determine the presence of four natural phonological processes. Results showed that when new information (comment) was conveyed by the child, phonological process use decreased. This contrasted with old information (topic), which was associated with a higher percentage of phonological errors. These results suggest that children may change their phonological performance when there is a need to convey new information. This further suggests that comments is at least one specific pragmatic function which is a 
motivational factor contributing to the "tuning up" of phonological production toward the adult standard.

In summary, the previous research examined a variety of factors that influence children's phonological performance. Associations were found between phonological process use and language form and content; however, there was little information pertaining to the effect of language use on phonological performance. Pragmatic contexts, specifically assertive versus responsive utterances, may motivate children to produce the most intelligible pronunciations they have available. Associations made between specific pragmatic functions and phonological performance would aid in the understanding of children's progression toward adult phonological forms. 
CHAPTER III

METHODS AND PROCEDURES

SUBJECTS

Thirty children between the ages of 36 and 45 months serve as subjects for this study. All are participants in the Portland Language Development Project (PLDP), an ongoing, longitudinal study of outcomes of early language delay.

Subject Description at Intake: Age 2

The subjects were recruited for a longitudinal study from local pediatric clinics and newspaper ads. The parents of subjects signed permission forms to participate in the study during the initial assessment at Portland state University, when the subjects were 20-34 months of age. The parents provided the following information by completing a questionnaire: (a) parents' occupations, (b) child's date of birth, (c) number different words used by the child, and (d) whether or not the child puts words together to form short phrases or sentences. These children were then divided into two diagnostic groups: normal and late talkers (Lts). Subjects placed in the normal group produced more than 50 different words of the Language Development survey 
(LDS) (Rescorla, 1989). The LDS is a questionnaire which asks parents to identify which of 300 of the most common words in children's early vocabularies the child produces. It has been shown to have high reliability, validity, sensitivity and specificity for identifying language delay in toddlers. Subjects in the LT group used fewer than 50 different words on the LDS (Rescorla, 1989). The groups were matched for chronological age, race, sex, and socioeconomic status (SES). The SES was based on a four-factor index using the parents' occupational and educational status. This procedure provided scores of 1 to 5, with 1 being the highest SES level and 5 being the lowest (Myers \& Bean, 1968)

In order to participate in the study, subjects had to pass a speech reception screening at $25 \mathrm{~dB}$. This screening was conducted by graduate audiology students under the supervision of an audiology instructor or by the audiology instructor. The children also had to have no known physical handicaps, neurological disorders, or autism, which was determined by a review of medical history and observation by the investigators. The subjects also had to score 85 or higher on the Bayley Scales of Infant Development (Bayley, 1969 ) or the Stanford-Binet Intelligence Scale (Termin \& Merrill, 1960), depending on their age. Subjects have been seen yearly for in-depth follow-up evaluation for speech, 
language, and related skills since the initial intake assessment at 20-34 months.

Subjects in Present Study: Age 3

The subjects in the present study are a subset of those in the PLDP. For purposes of the present research, two groups were formed. The first group, which consisted of 15 subjects, was identified as normal speakers. They had been placed in the normal group at intake. At the follow-up evaluation at age 3 , they scored above the 15th percentile on the Goldman-Fristoe Test of Articulation (Goldman \& Fristoe, 1969), as well as on a battery of language tests, including the Developmental Sentence Score (Lee, 1974) which measures grammatical expression in spontaneous speech. The second group, referred to as the "speech-delayed" group, also consisted of 15 subjects. They were children identified as late talkers at 20-34 months. These subjects scored at or below the loth percentile on the Goldman-Fristoe Test of Articulation (Goldman \& Fristoe, 1969 ) at the follow-up evaluation at age 3 . These children as a group were also delayed in expressive language. The speech-delayed group had a mean score of 3.70 on the Developmental Sentence Score (Lee, 1974). This score was below the loth percentile for normal 3-year-olds and indicates the speech-delayed group also had language involvement in their disorder. Demographic data for the two groups is given in Table II. 
TABLE II

SUMMARY OF DEMOGRAPHIC DATA

\begin{tabular}{lcclc}
\hline Group & $\begin{array}{c}\text { Mean age } \\
\text { in months }\end{array}$ & SES $^{a}$ & Race & Sex \\
Normal & 38.18 & 2.77 & $91 \%$ White & $68 \%$ Male \\
Speech- & 38.66 & 2.86 & $77 \%$ White & $73 \%$ Male \\
delayed & & & $22 \%$ Minority & $27 \%$ Female \\
\hline
\end{tabular}

${ }^{a}$ Socioeconomic status based on a scale of 1 to 5 with 1 being the highest and 5 being the lowest.

\section{PROCEDURES}

Children who participated in the longitudinal study were seen for follow-up assessment at age 3, at least 1 year after the initial assessment. At that time, the Goldman-Fristoe Test of Articulation (Goldman \& Fristoe, 1969) was administered along with a battery of standardized language tests. In addition, a free speech sample was collected on audiotape during a 10-minute play interaction between mother and child. This sample was analyzed for Developmental sentence score according to procedures described by Lee (1974). The speech sample also provided the basis for the phonological analysis reported here. 


\section{INSTRUMENTS AND PROCEDURES}

The Goldman-Fristoe Test of Articulation (Goldman \& Fristoe, 1969) was administered by graduate-level students in speech and Hearing Sciences. Rapport with the subjects was established before testing was begun. Tests were administered in a quiet room with the examiner and subject facing one another across the corner of a table. The articulation testing was performed by various graduate students trained in the administration of this particular test. The authors of the Goldman-Fristoe Test of Articulation established that test-retest reliability was 95\%. Inter-rater reliability and intra-rater reliability were found to be $92 \%$ and $91 \%$, respectively.

\section{Speech Samples}

The parent and child were provided with a standard set of toys to play with during the taping session. Each parent was instructed before each taping procedure to play with their child as normally as they would at home. Each sample was audiotaped on a Sony BM80 transcribing tape recorder using an ECM-D8 Electret Condenser microphone. Samples were transcribed orthographically for Developmental Sentence Score Analysis.

\section{Phonological Analysis}

The previously recorded conversational speech samples provided the data for the phonological analysis. Utilizing 
the audiotape, the first appearance of each utterance in the sample was transcribed using broad phonemic transcription and the International Phonetic Alphabet. Judgments were then made, concerning the particular pragmatic function of each of the utterances, through analysis of the conversational context in which each utterance was made. Through this analysis, child utterances were designated either assertive or responsive. Pragmatic categories were defined as follows (Fey, 1986).

Assertive conversational acts consisted of:

1. Requestives: An attempt to obtain information or actions from others, including requests for information, action, clarification, and attention.

2. Assertives: Comments, statements, and disagreements.

3. Performatives: Claims, jokes, teasing, protests and warnings.

Responsive conversational acts consisted of:

1. Responses to requests for information: Attempts to provide new information requested by the partner.

2. Responses to requests for action: Verbal accompaniments to the performance of the action requested by the partner.

3. Responses to requests for clarification: Attempts to repeat or otherwise clarify a prior utterance following the partner's request for clarification. 
4. Responses to requests for attention: Responses to attentional requests that serve to acknowledge the partner an to indicate that the partner may continue.

5. Responses to assertives and performatives: Acknowledgments of or agreements with prior partner utterances that add no new information to the prior utterance.

The words containing simplifications were further analyzed using the Programs to Examine Phonetic and Phonologic Evaluations Records (Pepper Program) (Shriberg, 1986) to interpret the phonological processes used. After each of the phonological processes within each utterance had been recorded, percentages of occurrence of phonological processes were established for each pragmatic category within each diagnostic classification.

\section{Reliability}

Point-to-point reliability scoring of the Goldman-Fristoe Test of Articulation was $90 \%$ based on an independent on-line scoring of $10 \%$ of the tests administered. Ten percent of the transcripts were independently re-scored by a second graduate student for assignment of utterances to pragmatic categories and for accuracy of phonemic transcription. Reliability of assignment of utterances to pragmatic categories was $95 \%$. Reliability of phonetic transcription, based on point-to-point (phoneme-to-phoneme) was $91 \%$ 
CHAPTER IV

\section{RESULTS AND DISCUSSION}

\section{RESULTS}

The data gathered from the normal and speech-delayed groups were compared in terms of the mean percentage of phonological process use for both pragmatic categoriesassertive and responsive. A number of multiple comparisons were statistically performed, analyzing various components of the collected data.

The overall percentage of process use computed for each diagnostic group were analyzed according to the Pepper Program. The program assigns a severity ranking based on the percentage of processed used (Shriberg, 1986). Based on the Pepper Program, the overall phonological process use of $15 \%$ or less represents a mild severity ranking.

\section{HYPOTHESIS}

The following research hypothesis was tested in this study: There will be a significantly greater number of phonological simplification processes used on words expressing responsive as opposed to assertive speech acts in both normal and speech-delayed 3-year-olds. 
A one-tailed $t$ test was used to compare the mean number of phonological processes used in assertive and responsive utterances for each of the two diagnostic groups at a significance level of $\underline{p}<.05$. The null hypotheses, as stated above, was not rejected, indicating there was no significant difference in the phonological performance between the assertive and responsive utterances for either group. The results of the comparison of the two sets of means are reported in Table III. It can be seen there that the delayed group was functioning in the mild range of speech impairment with process use at 10-12\%.

The data were analyzed further to examine whether there were differences in phonological process use between the two diagnostic groups. Significant differences were

TABLE III

RESULTS OF ONE-TAILED $t$ TESTS COMPARING MEAN PERCENTAGE OF PHONOLOGICAL PROCESS USE IN TWO PRAGMATIC CATEGORIES FOR TWO DIAGNOSTIC GROUPS

\begin{tabular}{lccc}
\hline Group & Assertive mean & Responsive mean & $\underline{t}$ test $^{a}$ \\
\hline Normal & 5.88 & 7.34 & -1.021 \\
Speech-delayed & -3.18 & -2.63 & -.838 \\
\hline
\end{tabular}

${ }^{a}$ Critical value of $\underline{t}=2.048$ (.05, inf.) 
found between the normal and speech-delayed groups in both the assertive and responsive categories. It was concluded that speech-delayed children used a significantly greater number of phonological processes when using both speech types. The results of the $t$ tests for this analysis are reported in Table IV.

Further analysis of the previous data was necessary to reveal any significant differences between the two group's assertive and responsive phonological performance. The difference between the percentage of use of phonological processes in the assertive and responsive categories was calculated for each subject in both groups. A comparison was made between the average differences found between the

TABLE IV

RESULTS OF ONE-TAILED $t$ TESTS COMPARING MEAN USE OF PHONOLOGICAL PROCESSES BETWEEN NORMAL AND DELAYED GROUPS IN BOTH PRAGMATIC CATEGORIES

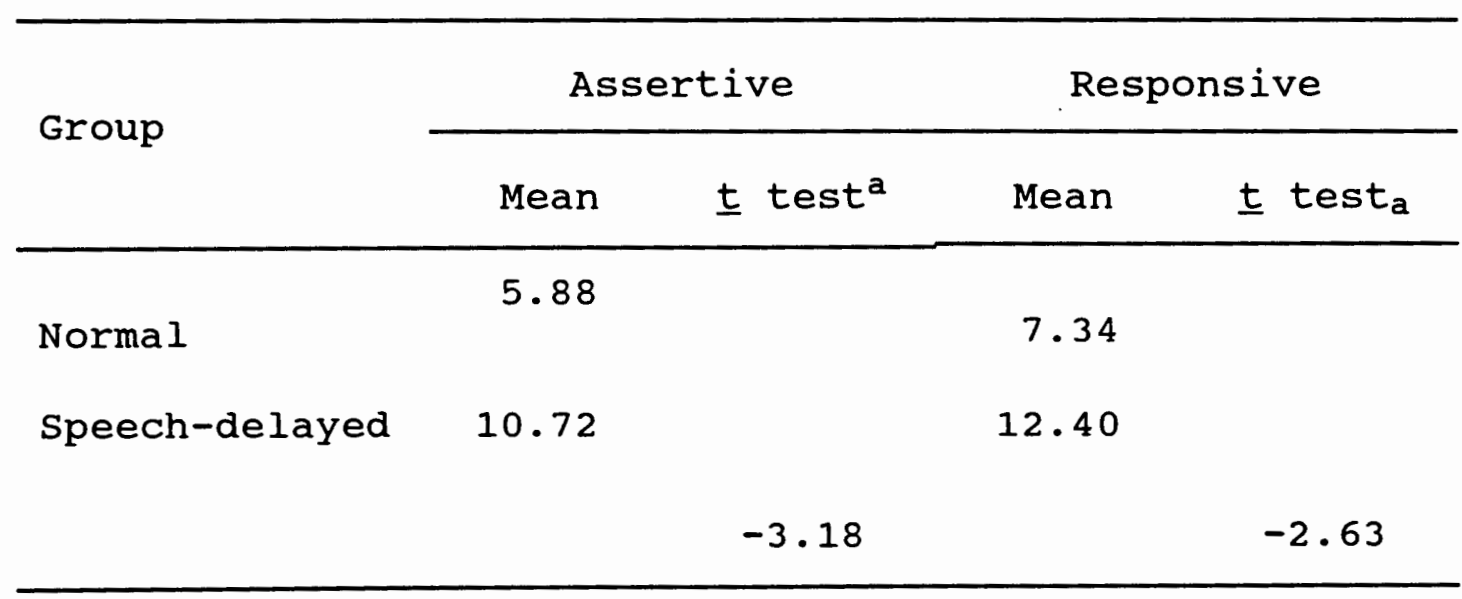

${ }^{a}$ Critical value of $t=2.048(.05$, inf.). 
two groups. No significant differences were found in the average difference between phonological performance in the two pragmatic categories for the two diagnostic groups. Therefore, it was concluded that the subjects from the normal and speech-delayed groups did not differ significantly in the amount of processes used in one category as opposed to the other. Results of the $\underline{t}$ test are reported in Table $\mathrm{V}$.

\section{Related Information}

Although the research hypothesis was not supported with the present data, related information was obtained to investigate other areas that may explain the observed

\section{TABLE V}

RESULTS OF ONE-TAILED $t$ TEST COMPARING AVERAGE DIFFERENCE BETWEEN PHONOLOGICAL PROCESS USE IN ASSERTIVE AND RESPONSIVE UTTERANCES FOR NORMAL AND SPEECH-DELAYED GROUPS

\begin{tabular}{lcc}
\hline Group & $\begin{array}{c}\text { Average } \\
\text { difference }\end{array}$ & $t$ test $^{a}$ \\
Normal & 1.453 & \\
Speech delayed & -1.673 & .181 \\
\hline
\end{tabular}

${ }^{a}$ Critical value of $\underline{t}=2.048$ (.05, inf.). 
findings. The following questions were researched to provide peripheral support of the hypothesis:

1. Are there differences in the percentage of unintelligible words within assertive and/or responsive utterances between the normal and speech-delayed groups? No significant differences were found in either the normal or the speech delay groups' intelligibility within either of the pragmatic functions. This data suggests that the speech-delayed group was only mildly delayed with phonological processes that did not significantly interfere with intelligibility. See Tables VI and VII for means and average difference between means of both groups.

2. Is there a significantly greater percentage of assertive utterances as opposed to responsive utterances

\section{TABLE VI}

RESULTS OF $\underline{t}$ TESTS COMPARING PERCENTAGE OF UNINTELLIGIBLE WORDS IN ASSERTIVE AND RESPONSIVE UTTERANCES WITHIN THE NORMAL AND SPEECH-DELAYED GROUPS

\begin{tabular}{lccc}
\hline Group & $\begin{array}{c}\text { Assertive } \\
\text { utterances }\end{array}$ & $\begin{array}{l}\text { Responsive } \\
\text { utterances }\end{array}$ & $t_{\text {test }}$ \\
Normal & 3.73 & 3.14 & .056 \\
Speech-delayed & 6.06 & 5.17 & 1.038 \\
t test $^{a}$ & -1.328 & -1.885 & \\
\hline
\end{tabular}

${ }^{a}$ Critical value of $t=2.048(.05$, inf.) 
TABLE VII

RESULTS OF A ONE-TAILED $t$-TEST COMPARING THE AVERAGE

DIFFERENCE IN EACH SUBJECT'S UNINTELLIGIBILITY

BETWEEN THE NORMAL AND SPEECH-DELAYED GROUPS

Group

Difference in

unintelligibility

Normal

.598

Speech delayed

.8926

$\underline{t}=-.214$

${ }^{a}$ Critical value of $\underline{t}=2.048$ (.05, inf.)

used by the normal or delayed groups? Data revealed that both groups used a significantly greater number of assertive utterances than responsive utterances. These results show that both groups on average are more assertive than responsive; however, the normal and speech-delayed groups do not differ when comparing the overall percentage of assertive and responsive utterances used. See Table VIII for results.

3. Does either group use a significantly greater mean length of response in either of the pragmatic categories? The length of response was recorded for each group in both assertive and responsive utterances. Results revealed that both the normal and speech-delayed groups used longer 
TABLE VIII

RESULTS OF ONE-TAILED $t$ TEST COMPARING AVERAGE PERCENTAGE OF ASSERTIVE AND RESPONSIVE UTTERANCES IN THE NORMAL AND SPEECH-DELAYED SPEECH SAMPLES

\begin{tabular}{lccc}
\hline Group & $\begin{array}{c}\text { Assertive } \\
\text { utterances }\end{array}$ & $\begin{array}{l}\text { Responsive } \\
\text { utterances }\end{array}$ & t test $^{a}$ \\
Normal & 64.94 & 35.06 & 7.476 \\
$\begin{array}{l}\text { Speech- } \\
\text { delayed }\end{array}$ & 60.54 & 39.46 & 3.66 \\
$t$ test $^{a}$ & .887 & -.893 & \\
\hline
\end{tabular}

${ }^{a}$ Critical value of $\underline{t}=2.048$ (.05, inf.)

responses in assertive utterances than responsive utterances. Also, the normal group used significantly longer responses than the speech-delayed group when performing assertive utterances. The average difference of each subject's length of assertive and responsive responses was calculated and compared between the two groups. Data revealed that the normal group used significantly longer responses in assertive utterances as opposed to responsive utterances. Refer to Table IX and $\mathrm{X}$ for data results.

\section{DISCUSSION}

The results of the data analysis showed that the phonological performance of the normal and speech-delayed 
TABLE IX

RESULTS OF ONE-TAILED $t$ TEST COMPARING MEAN LENGTH OF RESPONSE WITHIN THE ASSERTIVE AND RESPONSIVE

UTTERANCES IN THE NORMAL AND

SPEECH-DELAYED GROUPS

\begin{tabular}{lccc}
\hline Group & $\begin{array}{c}\text { Assertive } \\
\text { utterances }\end{array}$ & $\begin{array}{l}\text { Responsive } \\
\text { utterances }\end{array}$ & $t_{\text {test }}{ }^{a}$ \\
Normal & 4.10 & 3.59 & 5.67 \\
$\begin{array}{l}\text { Speech- } \\
\text { delayed }\end{array}$ & 3.17 & 2.21 & 3.74 \\
test $^{\mathrm{a}}$ & 3.13 & 1.749 & \\
\hline
\end{tabular}

${ }^{a}$ Critical value of $\underline{t}=2.048$ (.05, inf.)

groups was not significantly affected by interpersonal concerns stemming from the two pragmatic categories. The assertive speech productions did not aid in suppressing phonological process use as hypothesized.

These results differ from findings by Campbell and Shriberg (1982) who also examined the production of speech sounds within two pragmatic functions. The researchers found that speech-delayed children improved their phonological performance when they conveyed new information (comments) as opposed to old information (topics). The subjects used in the Campbell and Shriberg (1982) study were judged to be moderately to severely speech-delayed, in contrast to the mildly speech-delayed subjects in the 
TABLE $X$

RESULTS OF A ONE-TAILED $t$ TEST COMPARING THE AVERAGE

DIFFERENCE IN EACH SUBJECT'S LENGTH OF RESPONSE

BETWEEN ASSERTIVE AND RESPONSIVE UTTERANCES

BETWEEN NORMAL AND SPEECH-DELAYED GROUPS

Group Average difference

Normal

Speech-delayed

$\underline{t}$ test $^{a}$
1.512

.959

2.519

${ }^{a}$ Critical value of $\underline{t}=2.048(.05$, inf.)

present study. The differing severity levels of the subjects used in both studies could account for the divergent results. Therefore, although the mildly speech-delayed group in the present study used more phonological processes than the normal group, they were generally understandable to their listeners. The mildly speech-impaired children, as opposed to the moderately severely delayed, may not have been motivated to improve their phonological productions to the adult standard due to their higher intelligibility levels.

other findings in this study revealed that the length of utterance did not significantly affect phonological performance. The normal group was found to use longer utterances during assertive speech acts than the 
speech-delayed group. Although the speech productions were longer, providing more opportunities for phonological process use, the normal group demonstrated less phonological processes than the speech-delayed group. Similarly, the delayed group revealed significantly longer utterances during assertive speech acts than responsive speech acts. The use of phonological processes, however, did not significantly increase with length of utterance.

Both the normal and delayed groups were significantly more assertive than responsive during the analyzed speech samples; however, the increased percentage of assertive speech acts was not found to be a factor that influenced phonological performance. Neither group used significantly more processes during assertive utterances, although more opportunities for process use were available.

The two pragmatic categories examined in this study did not significantly impact the phonological performance of the normally developing and mildly speech-delayed 3-year-olds. This could be accounted for by the relatively high intelligibility of the speech-delayed group, making it unnecessary to improve their phonological skills to communicate effectively. 
CHAPTER V

SUMMARY AND IMPLICATIONS

SUMMARY

Research into the eventual suppression of phonological processes among children has centered on the influence of phonetic context and semantic-syntactic factors.

Researchers have described various factors that would account for the variability found in normal and speech-delayed children's use of phonological processes. Researchers have found associations between phonological process use and language form and content, although there is a paucity of information pertaining to the effect of language use on phonological performances.

This study examined the phonological process use within two pragmatic functions-assertive and responsive utterances-used by 15 normally developing and 15 speech-delayed 3-year-olds. These groups were matched for age, sex, and socioeconomic status, all passed a hearing screening at $25 \mathrm{~dB}$ and scored at least 85 on the Bayley Scales of Infant Development or the Stanford-Binet Intelligence scale.

A 10-minute parent/child speech sample of each 3-year-old was orthographically and phonetically 
transcribed. Each first occurrence utterance was coded as either assertive or responsive, depending on the particular pragmatic function it served. Percentage of phonological process use was determined for both groups within each pragmatic category after analysis using the Pepper Program. Data were analyzed for significant differences between the two groups in the percentage of phonological processes used within the assertive and responsive categories. Results indicated that the speech-delayed group used more processes in both categories, although pragmatic function of the utterances did not have a significant effect on percentage of phonological processes used by either group. It was noted that children in the speech-delayed group were only mildly delayed, thus making them fairly intelligible to their listeners. Both groups were more assertive than responsive and used longer utterances during assertive speech acts; however, neither factor appeared to have any bearing on their phonological performances.

It was concluded that the two groups appeared to show no significant difference in their phonological performances when comparing one pragmatic category to the other. Results indicated that the assertive speech acts examined held no motivation factors that influence the phonological 
performance of normal or mildly speech-delayed 3-year-olds when compared to responsive speech acts.

\section{IMPLICATIONS}

\section{Research}

Additional research into the factors that influence children's phonological performance is necessary to develop a clear understanding of normal and speech-delayed phonological progression to the adult standard. Replication of the current study could provide information about other pragmatic functions that may influence phonological process use. Such replications among subjects with mild, moderate, and severe speech delays could be valuable in establishing those factors that internally motivate children with varying speech skills to improve their intelligibility.

Analysis of assertive utterances could provide further information relating to the phonological performance of normal and speech-delayed children. Comparisons could be made of children who are less assertive than those who have an increased number of assertive utterances. Analysis of phonological process use between these groups could reveal differences that show "tuning up" of phonological skills during assertive speech acts.

Follow-up studies involving normal and speech-delayed subjects and any further replications of this study should be conducted to describe the variables that motivate both 
groups of children to decrease phonological process use. Further analysis of specific pragmatic factors that influence phonological performance could reveal possible motivating factors that constitute a need for great intelligibility. Such discoveries would have strong clinical applications.

\section{clinical}

The major clinical implications derived from this study are revealed in the significantly shorter mean length of response used by the speech-delayed subjects when compared to the normal group. It was found that the speech-delayed group used shorter responsive utterances than assertive utterances. In order to increase the speech-delayed children's mean length of utterance, clinicians could begin using expansion techniques during responsive speech acts as a base. As the responsive utterances increased in length, the clinicians could then expand upon the children's assertive speech acts. This clinical procedure would render the speech-delayed children with communication abilities more similar to those of the normally developing children. 


\section{REFERENCES}

Amidon, H. F. (1941). A statistical study of relationships among articulatory errors made by one hundred first grade children. Unpublished master's thesis, University of Iowa, Ames.

Bayley, N. (1969). Bayley scales of infant development. New York: Psychological Corporation.

Camarata, S. M., \& Schwartz, R. G. (1985). Production of object words and action words: Evidence for a relationship between phonology and semantics. Journal of Speech and Hearing Research, 28, 323-330.

Campbell, T. F., \& Shriberg, L. D. (1982). Associations among pragmatic functions, linguistic stress, and natural phonological processes in speech-delayed children. Journal of Speech and Hearing Research, $\underline{25}, 547-533$.

Curtis, J.F., \& Hardy, J. C. (1959). A phonetic study of misarticulation of $/ r /$. Journal of Speech and Hearing Research, $\underline{2}$, 244-257.

Edwards, M. L., \& Shriberg, L. D. (1983) . Phonology: Applications in communication disorders. San Diego: College-Hill Press.

Faircloth, M. A., \& Faircloth, S. R. (1970). An analysis of the articulatory behavior of a speech-defective child in connected speech and in isolated-word responses. Journal of Speech and Hearing Disorders, 35, 51-61.

Fey, M. E. (1986). Language intervention with young children. San Diego: College-Hill Press.

Gallagher, T. M., \& Shriner, T. H. (1975a). Articulatory inconsistencies in the speech of normal children. Journal of Speech and Hearing Research, 18, 168-175.

Gallagher, T. M., \& Shriner, T. H. (1975b). Contextual variables related to inconsistent /s/ and /z/ production in the spontaneous speech of children. Journal of Speech and Hearing Research, 18, 623-633. 
Gallagher, T. M. (1977). Revision behaviors in the speech of normal children developing language. Journal of Speech and Hearing Research, 20, 303-318.

Goldman, R., \& Fristoe, M. (1969). Goldman-Fristoe test of articulation. Circle Pines, MN: American Guidance Services.

Haelsig, P., \& Madison, C. (1986). A study of phonological processes exhibited by $3-, 4-$, \& 5-year-old children. Language, Speech, and Hearing services in Schools, 17, 107-114.

Ingram, D. (1981). procedures for the phonological analysis of children's language. Baltimore: University Park Press.

Lahey, M. (1988). Lanquage disorders and language development. New York: Macmillan.

Lee, L. (1974). Developmental sentence analysis. Evanston, IL: Northwestern University Press.

Leonard, L. (1971). A preliminary view of information theory and articulatory omissions. Journal of Speech and Hearing Disorders, 36, 511-517.

Leonard, L. B. (1973). The nature of deviant articulation. Journal of Speech and Hearing Disorders, 38, 156-161.

Levy, L., Schlesinger, I. M., \& Braine, M. D. (1988). Categories and processes in language acquisition. Hillsdale, NJ: Lawrence Erlbaum Associates.

Myers, J. K., \& Bean, L. L. (1968). A decade later: A follow-up of social class and mental illness. New York: Wiley and Sons.

Olmstead, D. L. (1971). out of the mouths of babes: Earliest stages in language learning. The Hague, Paris: Mouton Co.

Owens, R. E. (1984). Language development (2nd ed.). Columbus, $\mathrm{OH}$ : Merrill Publishing.

Panagos, J. M., Quine, M. E., \& Klich, R. J. (1979). Syntactic and phonological influences on children's articulation. Journal of Speech and Hearing Research, $\underline{22}, 841-848$. 
Paul, R., \& Shriberg, L. D. (1982). Associations between phonology and syntax in speech-delayed children. Journal of Speech and Hearing Research, 25, 536-574.

Rescorla, L. (1989). The language development survey: A screening tool for delayed language in toddlers. Journal of speech and Hearing Disorders, 54, 587-599.

Shriberg, L. (1986). Programs to examine phonetic and phonologic evaluations records: Pepper. Madison, WI: University of Wisconsin Board of Regents.

Shriberg, L., \& Kwiatkowski, J. (1980). Natural processes analysis. New York: Wiley and Sons.

Siegel, G. M., Winitz, H. \& Conkey, H. (1963). The influence of testing instruments on articulatory responses of children. Journal of Speech and Hearing Disorders, 28, 67-76.

Snow, K. (1963). A detailed analysis of articulation responses of "normal" first grade children. Journal of Speech and Hearing Research, 6 , 277-290.

Spriestersbach, D. C., \& Curtis, J. F. (1951). Misarticulations and discrimination of speech sounds. Quarterly Journal of Speech, 37, 483-491.

Stampe, D. A. (1973). Dissertation on natural phonology. Unpublished doctoral dissertation, University of Chicago, Illinois.

Stoel-Gammon, C., \& Dunn, C. (1984). Normal and disordered phonology in children. Baltimore: University Park Press.

Termin, L., \& Merrill, M. (1960). Stanford-Binet Intelligence Scale. Boston: Houghton Mifflin.

Weiner, F. F., \& Ostrowski, A. S. (1979). Effects of listener uncertainty on articulatory inconsistency. Journal of Speech and Hearing Disorders, 44, 487-493.

Weiss, C. E., Gordon, M. E., \& Lillywhite, H. S. (1987). Clinical management of articulatory and phonologic disorders. Baltimore: Williams and Wilkens.

Wells, G. (1981). Learning through interaction. New York: Cambridge University Press. 
Wilson, L. (1945). A survey of speech defects among mentaliy retarded pupils in the public schools of Des Moines, Iowa. Unpublished master's thesis, University of Iowa, Ames.

Winitz, H. (1969). Articulatory acquisition and behavior. New York: Meredith Corp. 